\title{
Effect of Elaborative Text Modification on Pre- intermediate Male and Female EFL Learners' Reading Comprehension
}

\author{
Shahram Esfandiari Asl \\ Department of English Language, Ardabil Branch, Islamic Azad University, Ardabil, Iran \\ Asgar Mahmoudi \\ Department of English Language, Ardabil Branch, Islamic Azad University, Ardabil, Iran
}

\begin{abstract}
The current study was carried out to investigate whether elaborative text modification improves reading comprehension ability of pre-intermediate male and female EFL learners. To do this, 60 preintermediate learners were chosen based on their performance on a standard version of Longman's New Opportunities Placement Test. The participants also received a piloted version of a researcher-made reading comprehension test as the pretest to ascertain their homogeneity. The participants were then divided into two equal groups to represent the experimental and the control groups. Each group was further subdivided into male and female groups. Five reading passages in two formats (unmodified and elaborated) were administered to the participants in five weeks which was followed by a posttest. The experimental group received the elaborated texts, while the control group received the unmodified baseline texts. The results of a Two-way ANOVA indicated no significant effect for gender but there was a significant difference between the experimental and the control groups' reading comprehension. Findings of the study suggest that elaborative text modification can be a worthy option in EFL reading classes.
\end{abstract}

Index Terms —elaboration, text modification, input hypothesis, reading comprehension

\section{INTRODUCTION}

Reading comprehension has drawn the attention of many second and foreign language researchers, and has been studied from different perspectives. This is because, reading is the most important source of input for second language learners. However, input needs to be comprehended by second language learners for acquisition to take place (Chaudron, 1985).

Facilitating the process of reading for second or foreign language learners is of high priority for language researchers, teachers, and, of course, language learners. The question of how to make the reading process easier and more effective has resulted in the creation of a wide variety of theories, approaches and texts (Esfandiari Asl \& Zoghi, 2016). Recent research on input modification addresses the relative effectiveness of two different types of modification: simplification and elaboration (Oh, 2001). It is claimed that if elaborated textual material is provided, EFL learners' reading comprehension will improve. This study addressed the effect of this type of modification on reading comprehension of pre-intermediate EFL students. It also investigated the effect of gender on EFL students' reading comprehension after modifying the texts to which they were exposed. Generally, a brief look at the related literature reveals that the findings are mixed and we are still in need of further research to confirm or disconfirm the effectiveness of elaborative text modification and its interaction with gender of the participants. This study was carried out to answer the following research questions:

$\mathbf{R Q}_{1}$ : Does elaborative text modification have any significant effect on pre-intermediate EFL learners' reading comprehension?

$\mathbf{R Q}_{2}$ : Does gender have any significant effect on pre-intermediate EFL learners' reading comprehension?

$\mathbf{R Q}_{3}$ : Can any significant interaction effect be identified between text elaboration and gender in terms of intermediate EFL learners' reading comprehension?

Three null research hypotheses were derived from the above research questions as follows:

$\mathbf{H O}_{1}$ : Elaborative text modification does not have any significant effect on pre-intermediate EFL learners' reading comprehension.

$\mathbf{H O}_{2}$ : Gender does not have any significant effect on pre-intermediate EFL learners' reading comprehension.

$\mathbf{H O}_{3}$ : No significant interaction effect can be identified between text elaboration and gender in terms of intermediate EFL learners' reading comprehension. 
There is a plethora of theoretical and empirical studies and research reports on the effectiveness of pre-modification of input in language teaching and learning (Kim, 2006; Maxwell, 2011; Ragan, 2006; Oh, 2001; Yano, Long, \& Ross, 1994). But a review of the literature indicates that there is a scarcity of empirical research dealing with elaborative text modification and its effect on reading comprehension of male and female EFL learners in Iran.

Maxwell (2011) compared the effects of simplification and elaboration and found no indication of a significant effect that text modification can have on elementary ESL learners' reading comprehension. Brewer (2008) investigated if lexical simplification and modification had any effect on his learners' sentence-level comprehension. As in the case of Maxwell's study, the results of the test showed no significant difference in comprehension for items that had been simplified, elaborated, or left intact. In a study of L2 Korean learners, Kong (2007) showed that both simplified and elaborated input promoted the participants' reading comprehension yet again with no significant difference between the two. Chung (1995, as cited in Urano, 2000) hypothesized that both simplification and elaboration would facilitate L2 reading comprehension. Esfandiari Asl \& Zoghi (2016), too, found no significant difference between the elaborated and baseline conditions.

Young (1999) concluded that simplification, as another kind of text modification, will not necessarily aid comprehension of a text, a point that reflected findings referred to above in relation to elaboration. Pica, Doughty, and Young (1986) also found that simplification is not superior to elaborative modification, at least not consistently. Loschky (1994) even went on to say that not only pre-modified input can sometimes fail to improve learners' comprehension but also it can be detrimental to their comprehension.

The majority of research (e.g., Jeong, 1987; Lee, 1986; Oh, 2001; Strother \& Ulijn, 1987, as cited in Oh, 2001; Yano et. al., 1994) has been centered on the effects of simplifying the vocabulary and syntax of written texts. Studies done on the effects of simplification and elaboration on aural input comprehension and retention have been limited; but these studies have overwhelmingly shown that both of these techniques enhance comprehension with elaboration being more effective than linguistic simplification (Chaudron, 1983).

Mary E. O'Donnell (2005) argued that L2 readers of short literary texts modified elaboratively can recall more information of the texts they have read. Students reading these types of texts are able to identify more of the vocabulary that appear within the text. Kim (2003) stated that input modified by elaboration is preferred in SLA on the grounds that elaborated input retains the original material that L2 learners need for developing their interlanguge (as cited in Xiaohui, 2010).

Following the same line of investigation, Urano (2002) confirmed that lexical elaboration is superior to lexical simplification in terms of L2 reading comprehension as well as vocabulary acquisition. Ellis (1995), likewise, revealed that interactionally modified input, which is similar to elaboration, is more effective in vocabulary acquisition. Long (1983), in a similar vein, showed that modification is helpful in the amount of perceived comprehension. Ragan (2006) too, adopting a psychological approach, stated that elaborative text modification might help alleviate the difficulties less skilled readers have when relying on imprecise or incorrect background knowledge.

In regard to gender, Bugel and Buunk (1996) found that males outperformed females on passages about cars and football players, while females outperformed males on readings about midwives, and sad stories. Brantmeier (2002) reported no significant difference arising from gender in the comprehension of passages. Wei Wei (2009) studied the relationship between gender differences and reading comprehension in China. The findings indicated that female learners are more global and prefer guessing meaning from context while male learners are more analytic and attend more to words. Peart \& Barrnett (2013) examined the effects of gender on Spanish L2 reading comprehension. In this study participants read three literary passages and completed two measures that assessed their reading comprehension. Statistical analysis demonstrated a significant difference between female and male participants' comprehension of passages' content. These mixed findings support the idea that more empirical studies on the effect of gender on reading comprehension are needed.

\section{Methodology}

Participants of the current study were 60 pre-intermediate male and female EFL students selected from among the 90 students studying at Rose Language Institute in Ardabil, Iran. All of the participants enjoyed the same level of language proficiency according to their performance on the standard placement test (Longman's New Opportunities Placement Tests) given to them prior to beginning of the study. The participants who were at the pre-intermediate level of proficiency were divided into two equal experimental and control groups. Each of these groups was further subdivided into two separate only-male and only-female classes of 15.

Following the study done by Esfandiari Asl \& Zoghi (2016), after assigning the chosen students to different groups, a researcher-made test of reading comprehension was developed based on the level of the learners. Two reading comprehension passages were selected from the book "Reading and Vocabulary Development 2 (Thoughts and Notions)" by Ackert and Lee (2005). After that, 20 items in different formats, namely, MCQs, T/F, and open-ended were developed based on the same passages. The test was piloted among 30 students with the same characteristics (age, gender, level) for calculating its reliability. The test was then evaluated and malfunctioning and non-functioning items were either discarded or corrected. The results represented that the mean and standard deviation of the revised test were 13.5 and 1.61, respectively, with a reliability index of .74 as calculated by KR-21 formula. 
This test, which comprised 20 items, was used both as the pre-test and post-test in the present study to measure and compare the participants' reading comprehension before and after the study. The pretest was administered at the beginning of the study in order to ensure homogeneity of the learners reading comprehension ability. The posttest was administered at the end of the experiment to check for the effect of the treatment on the reading comprehension ability of the learners.

The five selected texts for treatment purposes were all relatively short, ranging from 142 to 246 words in unmodified form. To prepare the elaborated version of the texts, all of baseline texts underwent modification and two packages of baseline and elaborated texts were prepared to be used in the control and experimental groups, respectively.

Elaboration has been shown to increase text length (Rose, Souza, \& Hanna, 1996). The elaborated versions ranged from 217 to 429 words. Readers of the elaborated versions were expected to read the passages and answer the following multiple- choice reading comprehension questions in the same amount of time as the students who read the unmodified texts. The students received approximately fifteen minutes to read each passage and respond the following questions.

At final stage of the data collection process, the answer sheets were scored and the data were tabulated. To get as accurate results as possible, and to accept or reject hypotheses of the study, various data analyses techniques were used throughout the study the list of which goes as follows:

1. Descriptive statistics of pre- and post-test

2. Normality tests

3. A One-way ANOVA run on the reading comprehension pretest scores to determine homogeneity of the groups

4. A Two-way ANOVA to measure the main and interaction effects

\section{RESULTS AND DiSCUSSION}

As the first step in data analysis, it was necessary to check if the distribution of scores were normal at the pretest stage to warrant the use of ANOVA for finding the possible difference(s) among the groups. Table I shows the results of a 1-sample K-S test run on the pretest scores for this purpose. All of the obtained Sig. values are above .05 which point to the normality of the distributions.

TABLE I.

NORMALITY TESTS RUN ON PRETEST SCORES

\begin{tabular}{|c|c|c|c|c|c|}
\hline & & $\begin{array}{l}\text { male con } \\
\text { pretest }\end{array}$ & $\begin{array}{l}\text { male experimental } \\
\text { pretest }\end{array}$ & $\begin{array}{l}\text { female control } \\
\text { pretest }\end{array}$ & $\begin{array}{l}\text { female experimental } \\
\text { pretest }\end{array}$ \\
\hline $\mathrm{N}$ & & 15 & 15 & 15 & 15 \\
\hline \multirow{2}{*}{ Normal Parameters ${ }^{\mathrm{a}, \mathrm{b}}$} & Mean & 14.8000 & 14.4000 & 14.0667 & 14.0667 \\
\hline & Std. Deviation & 2.30527 & 1.76473 & 2.31352 & 1.98086 \\
\hline Test Statistic & & .165 & .166 & .147 & .113 \\
\hline Asymp. Sig. (2-tailed) & & $.200^{\mathrm{c}, \mathrm{d}}$ & $.200^{\mathrm{c}, \mathrm{d}}$ & $.200^{\mathrm{c}, \mathrm{d}}$ & $.200^{\mathrm{c}, \mathrm{d}}$ \\
\hline
\end{tabular}

a. Test distribution is Normal.

To be able to use One-way ANOVA, it is also necessary to check for the homogeneity of the groups as its other assumption. Table II shows the result of this test. From the Sig. value larger than .05, it is clear that this assumption has not been violated and therefore running One-way ANOVA was authorized.

TABLE II.

HOMOGENEITY OF VARIANCES AT THE PRETEST STAGE

\begin{tabular}{llll}
\hline Levene's Statistic & df1 & df2 & Sig. \\
\hline .880 & 3 & 56 & .457 \\
\hline
\end{tabular}

Table III, which reflects the result of the One-way ANOVA run on the pretest scores, indicates that the groups have not been different from each other in terms of their reading comprehension ability at $P=.95$ level with $F(3,56)=.412$, $\alpha=.745>.05$ at the beginning of the study.

TABLE III.

ANALYSIS OF VARIANCE RUN ON THE PRETEST SCORES

\begin{tabular}{llllll}
\hline & Sum of Squares & df & Mean Square & F & Sig. \\
\hline Between Groups & 5.467 & 3 & 1.822 & .412 & .745 \\
Within Groups & 247.867 & 56 & 4.426 & & \\
Total & 253.333 & 59 & & & \\
\hline
\end{tabular}

Findings from the pretest data analysis revealed that the groups had not been significantly different from each other in terms of reading comprehension and therefore any difference identified at the posttest stage could confidently be attributed to the effect(s) of the independent variables on the dependent variable. Since there were two categorical variables (group and gender) each with two levels and just one dependent variable (reading comprehension), the statistical procedure of choice was Two-way Analysis of Variance. It is necessary to point out that, the variable group at this stage was comprised of experimental and control groups.

The most important assumptions of the two-way ANOVA are as follows: 
- The samples must be normally or approximately normally distributed.

- The samples must be independent, that is, no participant should attend both conditions.

- The variances of the samples must be almost equal.

- The sizes of the samples must be the same.

Assumptions two and four were automatically satisfied in this study because all groups were of the same size and none of the participants attended both conditions. Assumptions one and three, however, needed examining. Table IV shows the results of normality tests run on the posttest scores for both experimental and control groups. As in the case of the pretest, all distributions were normal.

TABLE IV.

NORMALITY TESTS RUN ON POSTTEST SCORES

\begin{tabular}{|c|c|c|c|c|c|}
\hline & & $\begin{array}{l}\text { male con } \\
\text { posttest }\end{array}$ & $\begin{array}{l}\text { male experimental } \\
\text { posttest }\end{array}$ & $\begin{array}{l}\text { female control } \\
\text { posttest }\end{array}$ & $\begin{array}{l}\text { female experimental } \\
\text { posttest }\end{array}$ \\
\hline $\mathrm{N}$ & & 15 & 15 & 15 & 15 \\
\hline \multirow[t]{2}{*}{ Normal Parameters ${ }^{\mathrm{a}, \mathrm{b}}$} & Mean & 16.9333 & 15.2667 & 15.5333 & 15.1333 \\
\hline & Std. Deviation & 1.57963 & 1.09978 & 1.95911 & 1.64172 \\
\hline Test Statistic & & .183 & .204 & .183 & .201 \\
\hline Asymp. Sig. (2-tailed) & & $.186^{\mathrm{c}}$ & $.093^{\mathrm{c}}$ & $.188^{\mathrm{c}}$ & $.105^{\mathrm{c}}$ \\
\hline
\end{tabular}

Levene's test of homogeneity of group variances was also non-significant (Sig. =.09), as shown in Table V below.

TABLE V.

EQUALITY OF ERROR VARIANCES AT POSTTEST STAGE Dependent Variable: posttest scores

\begin{tabular}{llll}
\hline $\mathrm{F}$ & $\mathrm{df1}$ & $\mathrm{df} 2$ & Sig. \\
\hline 2.233 & 3 & 56 & .094 \\
\hline
\end{tabular}

Since all assumptions of the Two-way ANOVA were met, we were allowed to run this test to find out about the interaction and main effects of the independent variables on the dependent variable. Table VI shows the results of this test.

TABLE VI.

INTERACTION AND MAIN EFFECTS OF THE INDEPENDENT VARIABLES ON THE DEPENDENT VARIABLE

\begin{tabular}{|c|c|c|c|c|c|c|c|}
\hline Source & $\begin{array}{l}\text { Type III Sum of } \\
\text { Squares }\end{array}$ & df & Mean Square & $\mathrm{F}$ & Sig. & $\begin{array}{l}\text { Partial Eta } \\
\text { Squared }\end{array}$ & $\begin{array}{l}\text { Observed } \\
\text { Power }^{\mathrm{b}}\end{array}$ \\
\hline Corrected Model & $30.850^{\mathrm{a}}$ & 3 & 10.283 & 4.018 & .012 & .177 & .813 \\
\hline Intercept & 14820.817 & 1 & 14820.817 & 5790.459 & .000 & .990 & 1.000 \\
\hline Group posttest & 16.017 & 1 & 16.017 & 6.258 & .015 & .101 & .691 \\
\hline Gender posttest & 8.817 & 1 & 8.817 & 3.445 & .069 & .058 & .446 \\
\hline $\begin{array}{l}\text { Group posttest * gender } \\
\text { posttest }\end{array}$ & 6.017 & 1 & 6.017 & 2.351 & .131 & .040 & .326 \\
\hline Total & 14995.000 & 60 & & & & & \\
\hline Corrected Total & 174.183 & 59 & & & & & \\
\hline
\end{tabular}

As the first step in interpreting the results of a Two-way ANOVA we should look at the interaction effect. Finding a significant effect for interaction complicates the interpretation process because, according to Pallant (2013), to describe the influence of one of the independent variables the effect of the other should also be taken into account. Fortunately, in Table VI the Sig. value calculated for the interaction effect is larger than .05 which means that we should only look at the main effects of the independent variables. The lack of interaction between the independent variables is schematically represented in Figure I below by non-crossing lines. 


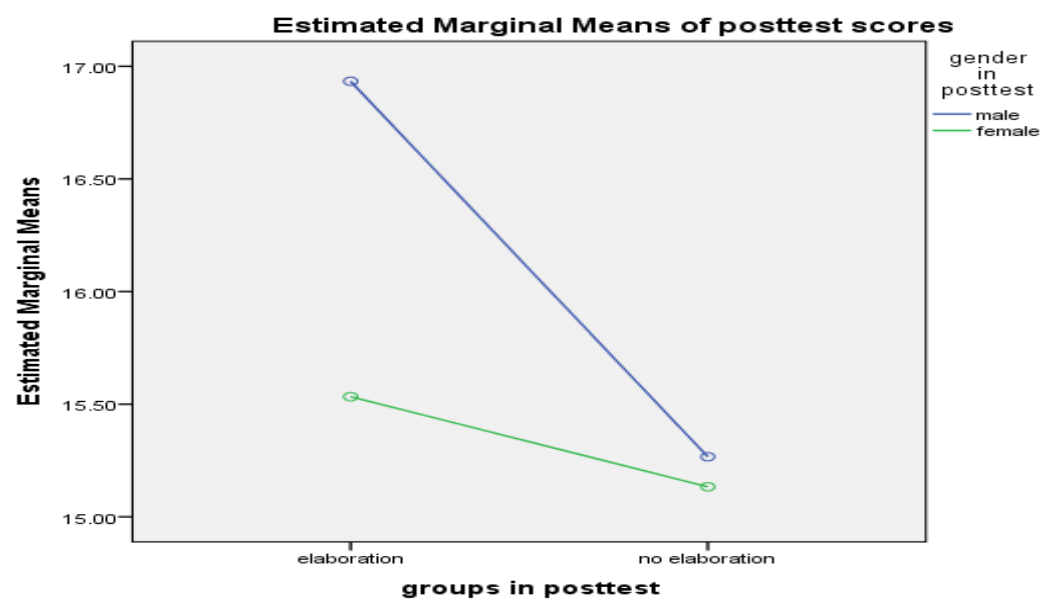

Figure I. Lack of interaction between the independent variables

The main effect for the instructional condition, specified as Group Posttest in Table VI, has been statistically significant, $F(2,56)=6.25, P=.015$. This finding suggests that without considering the gender difference, there has been a significant difference between the experimental and control groups' reading comprehension performance at the post-test stage. This means that the first null hypothesis of the research (Elaborative text modification does not have any significant effect on pre-intermediate EFL learners' reading comprehension) should be rejected.

The main effect for the independent variable gender is not statistically significant, $F(1,56)=3.44, P=.069$. That is, without considering the instructional conditions, there has been no difference between the male and the female groups in terms of their reading comprehension performance. Therefore, the second null hypothesis (Gender does not have any significant effect on pre-intermediate EFL learners' reading comprehension) was accepted. Finally, as explained above, there was no statistically significant interaction effect between the independent variables in relation to reading comprehension at the posttest stage, $F(1,56)=2.35, P=.13$. This indicates that the third research hypothesis (No significant interaction effect can be identified between text elaboration and gender in terms of intermediate EFL learners' reading comprehension) should be accepted.

\section{CONCLUSION}

This study was conducted to determine whether elaborative text modification can improve reading comprehension performance of Iranian pre-intermediate male and female EFL learners. To sum up the findings of the study, it can be said that, elaborative text modification had a statistically significant effect on the pre-intermediate EFL learners' reading comprehension. This finding is in conformity with the finding of Le (2011) who stated that regarding the effects of premodified input, input elaboration is likely to be a facilitating factor of students' comprehension (Esfandiari Asl \& Zoghi, 2016). The result also confirms findings about text elaboration by many other researchers (e.g., Brewer, 2008; Kong, 2007; Loschky, 1994; Maxwell, 2011; Pica, Doughty, \& Young, 1986).

The results, also, showed that there was no significant difference between the male and the female participants in terms of their reading comprehension performance. Brantmeier's (2003) study showed no significant difference between mean scores for males nad females on overall comprehension of the passages as revealed by ANOVAs run on the test results. However, she found that intermediate-level males outperformed females on a male-oriented passage and females outperformed males on a female-oriented passage. Brantmeier concluded that passage content clearly affected how male and female readers comprehended a passage. Mehrpour, Razmjoo, and Kian (2011), also, found that gender had no significant impact on learners' reading comprehension performance and vocabulary knowledge. While the previous results are not unanimous, the general consensus is that gender, along with the type of reading comprehension selected and assessment strategy (recall, sentence completion, and multiple choice) are all influential factors ( Peart \& Barrnett, 2013). These findings are in conflict with the finding of this study that gender has no significant effect on the reading comprehension of pre-intermediate EFL students.

As noted, simplification has some drawbacks elaborated on by several researchers. For example, Yano et al., (1994) concluded that linguistically simplified texts create less realistic models of the language which can negatively affect language learning. On the other hand, the technique of elaboration provides learners with opportunities to encounter, more or less, authentic materials and assist them in more successful comprehension. Elaboration, therefore, seems to constitute an important alternative to simplification for written input, and is worthy of greater attention by scholars, English language teachers, and EFL learners (Esfandiari Asl \& Zoghi, 2016).

The present study may augment our knowledge of the effectiveness of pre-modified input in general and elaborative text modification in particular. According to the results of this study, we can maintain that less proficient EFL learners' reading comprehension will enhance if teachers pay more attention to providing appropriate elaborated texts for them. In conclusion, it cannot be denied that input modification can promote comprehension, especially in reading and 
vocabulary learning (Esfandiari Asl \& Zoghi, 2016).

The limited framework of the current study does not allow broad generalizations of the results. This study, for example, did not consider the Interaction Hypothesis and its role in facilitating language learning. So, further research is needed to be done to deepen our understanding of the effects of modification and the way it facilitates reading comprehension.

\section{REFERENCES}

[1] Ackert, P., \& Lee, L. (2005). Concepts and comments. USA: Thomson.

[2] Brantmeier, C. (2003). Does gender make a difference? Passage content and comprehension in second language reading. Reading in a Foreign Language, 15(1), 1-27.

[3] Brewer, B. (2008). Effects of lexical simplification and modification on ESL readers' local-level perceived comprehension. Unpublished M.A. thesis, Brigham Young University.

[4] Bugel, K. \& Buunk, B. P. (1996). Sex differences in foreign language text comprehension: the role of interests and prior knowledge. Modern Language Journal, 80, 15-31.

[5] Chaudron, C. (1983). Simplification of input: topic restatement and their effects on L2 learners' recognition and recall. TESOL Quarterly, 17(3), 437-458.

[6] Chaudron, C. (1985). Intake: On models and methods for discovering learners' processing of input. Studies in Second Language Acquisition, 7, 1-14.

[7] Ellis, R. (1995). Modified oral input and the acquisition of word meanings. Applied Linguistics, 16(4), 409-441.

[8] Esfandiari Asl, Sh. \& Zoghi, M. (2016). The Effect of Elaborative Text Modification on Iranian EFL Learners' Reading Comprehension. Report and Opinion, 2016; 8(4).

[9] Kim, Y. (2006). Effects of input elaboration on vocabulary acquisition through reading by Korean learners of English as a foreign language. TESOL Quarterly, 40(2), 341-373.

[10] Kong, D. K. (2007). Effects of text modification on L2 Korean reading comprehension (Doctoral dissertation). Available from ProQuest Dissertations and Theses database.

[11] Le, H. T. X. (2011). Pre-modified input in second language learning. Hawaii Pacific University TESOL Working Paper Series, 9(1-2), 27-31.

[12] Long, M. (1983). Native speaker/ non- native speaker conversation and the negotiation of comprehensible input. Applied Linguistics, 4, 126-141.

[13] Loschky, L. (1989). The effects of negotiated interaction and premodified input on second language comprehension and retention (Master's thesis). Available from ProQuest Dissertations and Theses database.

[14] Mackey, A., \& Gass, S. M. (2005). Second language research: Methodology and design. New Jersey: Lawrence Erlbaum.

[15] Maxwell, S. (2011). The effects of two types of text modification on English language learners' reading comprehension: simplification vs. elaboration. Unpublished M.A. thesis, Hamline University.

[16] Mehrpour, S., Razmjoo, S. A., \& Kian, P. (2011). The relationship between depth and breadth of vocabulary knowledge and reading comprehension among Iranian EFL learners. Journal of English Language Teaching and Learning, 53(222), 97-127.

[17] O'Donnell, M. (2005). Use of textual elaboration with literary texts in intermediate Spanish. Unpublished doctoral dissertation, University of Iowa.

[18] Oh, S. Y. (2001). Two types of input modification and EFL reading comprehension: simplification versus elaboration. TESOL Quarterly, 35(1), 69-96.

[19] Pallant, J. (2013). SPSS survival manual (5th edition). City: Open University Press.

[20] Peart, S. M. \& Barrnett, B. S. (2013). Role of gender in Spanish L2 reading. En Diálogo de la Lengua, 5, 14-32.

[21] Pica, T., Doughty, C., \& Young, R. (1986). Making input comprehensible: Do interactional modifications help? ITL Review of Applied Linguistics, 72, 1-25.

[22] Ragan, A. (2006). Using adapted texts in ELL classrooms. The ELL Outlook, 5(2). Retrieved June 15, 2009 from http://www.coursecrafters.Com/ELL-outlook.

[23] Rose, J.C., Souza, D.G., \& Hanna, E.S. (1996). Teaching reading and spelling: Exclusion and stimulus equi valence. Journal of Applied Behavior Analysis, 29(4), 451-469.

[24] Urano, K. (2000). Lexical simplification and elaboration: Sentence comprehension and incidental vocabulary learning. Unpublished M.A. thesis, University of Hawaii at Mania.

[25] Wei Wei, V. (2009). Gender differences in reading comprehension for Chinese secondary school students (MA thesis, University of Wisconsin-Platteville).

[26] Yano, Y., Long, M., \& Ross, S. (1994). The effects of simplified and elaborated texts on foreign language reading comprehension. Language Learning, 44(2), 189-219.

[27] Young, D. J. (1999). Linguistic simplification of SL reading material: Effective instructional practice? Modern Language Journal, 83, 350-366.

Shahram Esfandiari Asl is an English language teacher. He is currently a PhD candidate of ELT at Islamic Azad University Ardabil Branch in Iran. His research interests include second language learning and teaching, form-focused instruction, feedback types, and reading comprehension.

Asgar Mahmoudi is an assistant professor of ELT at Islamic Azad University Ardabil Branch in Iran. He has been teaching different courses for M.A. and PhD students for about eight years. His research interests are theories of second language learning and teaching, syllabus design, applied linguistics, and statistics. 